\title{
Cobalt and Copper in Ruminant Nutrition
}

\author{
By Hedley R. Marston, E. W. Lines, R. Grenfell Thomas and I. W. McDonald \\ Council for Scientific and Industrial Research (Australia), Nutrition Laboratory, \\ University of Adelaide
}

\begin{abstract}
$\mathrm{A}^{\mathrm{s}}$ $S$ the successful use of supplements containing cobalt for the prevention of bush sickness in stock has given rise to a considerable amount of publicity in which the original source of information has been largely lost sight of, a brief résumé of the sequence of events that led to this application seems desirable.
\end{abstract}

The apparently essential nature of cobalt in the nutrition of ruminants was first suggested by a group of workers in the Council for Scientific and Industrial Research Nutrition Laboratory in the University of Adelaide, from experimental findings during the investigation of the etiology of 'coast disease', a malady which affects sheep confined in their grazing to the highly calcareous shell sand littoral of southern Australia. The dramatic response and rapid restoration observed to supervene when minute amounts of cobalt (1 mgm. a day as soluble salt) were administered to seriously affected animals was announced at the Australian and New Zealand Association for Advancement of Science during the January meeting in 1935 , when the close resemblance that coast disease bore to stock ailments known in different parts of the world as bush sickness (New Zealand), enzootic marasmus (Western Australia), pine (Cheviots and Inner Hebrides), nakaturuitis (Kenya), and salt sickness (Florida), was again stressed. This address was published a few months later.

The appearance of symptoms of lethargy, progressive wasting and anæmia in ruminants confined to certain restricted areas, and their rapid alleviation if the affected flocks are changed to a different type of country, has been recognized for many years. The description in 1807 of pining, daizing or vinkish by the Ettrick shepherd, James Hogg, suggests that this malady results from a deficiency, for the ". . . distemper . . . affects sheep confined to some districts . . . but removing them to fine land cures them immediately". The symptoms he reported later (1831) are those commonly recognized in the diseases mentioned above. McGowan and Smith's study of the distribution of pine disease in areas derived from porphorytic rocks on the Scottish side of the Cheviots, and Grieg and Dyrerre's investigation of the lethargic wasting as it occurs among sheep grazing exclusively on the shell sand beaches of the Isle of Tiree, led to the recognition of its similarity to bush sickness.
The New Zealand bush sickness, which occurs in areas usually defined by relatively recent volcanic showers, was referred to in the early reports of Park (1806) and later by Gilruth (1900). Guided by the hypothesis that the associated anæmia resulted from iron deficiency, Aston and his collaborators observed the benefit which followed dosing affected animals with massive amounts of iron salts, which, in the light of our present knowledge, it seems probable were contaminated with traces of other elements. For economic reasons, Aston suggested the use of the naturally occurring hydrated iron oxide, limonite, and this material, providing it originated from certain deposits, undoubtedly helped to control the disease.

The investigations of Filmer (1933) of a similar malady, enzootic marasmus, affecting both cattle and sheep grazed continually over certain highly ferruginous sandy loams of the Denmark district of Western Australia, led to the conclusion that while large doses of limonite prevented the occurrence of the malady and restored affected animals to normal health, pure iron salts were ineffective. Later, Filmer, in collaboration with Underwood, found hydrochloric acid extracts of limonite to be as active as the material itself, and the potency of these was unimpaired on removal of all but the faintest traces of iron. Underwood fractionated these extracts further; but, owing to the vagaries of the chemical methods and his dependence on so-called pure chemicals, the issue was temporally obscured.

Meanwhile, the investigations of coast disease had proved that therapy with carefully purified iron salts, either alone or in conjunction with copper and with liver extract, failed to arrest the progress of the symptoms. The maintenance of health of sheep which had free access to a complex salt mixture containing cobalt while pastured on affected country was observed, and the publication of the production of polycythæmia in rats by minute amounts of cobalt by the Walthners, led to the experiments that resulted in the immediate response which cobalt therapy brought about in animals suffering from coast disease. The implication that sheep suffering from enzootic marasmus would react similarly to cobalt was amply confirmed by Underwood and Filmer's demonstration following a short visit of Dr. Underwood to the Nutrition Laboratory, Adelaide, that small doses of cobalt rapidly restored affected animals to normal health. 
Reports of the variability of the response of bush sick animals to treatment with massive doses of limonite or of soluble iron salts led to the conclusion that Aston's iron deficiency hypothesis, although vigorously defended, was untenable. Rigg and Askew were unable to find a significant difference in the iron content of pastures from bush sick and healthy areas. They demonstrated later that ironfree extracts from healthy soils would completely and cure of bush sickness as it occurs at Morton Mains, and since then the treatment has been widely applied with obvious success in New Zealand.

The part undoubtedly played by cobalt in restoring and maintaining health in sheep suffering from the three maladies, coast disease, bush sickness, and enzootic marasmus, which although strictly regional, occur in markedly different terrain,

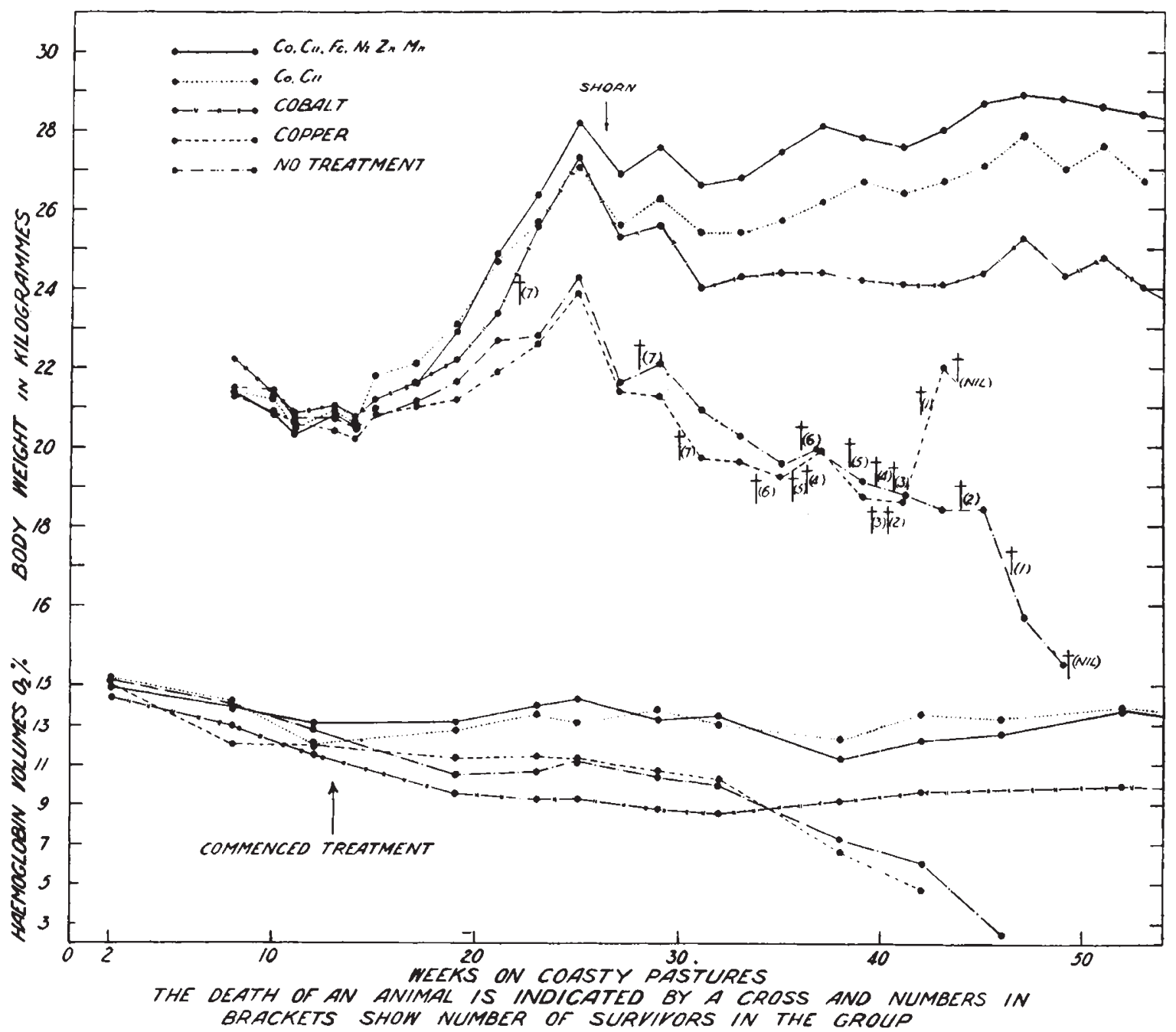

EFFECT OF COBALT AND COPPER ON YOUNG SHEEP DEPASTURED ON THE LITTORAL WHERE COAST DISFASE OCCURS. EACH MATCHED GROUP CONTAINS GIGHT LAMBS AGED 8 MONTHS AT BEGINNING OF THE EXPERIMENT. ALL WERE DEPASTURED TOGETHER, THE TREATED GROUPS RECEIVING THEIR SUPPLEMENTS IN AQUEOUS SOLUTION THREE TIMES WEEkIY. THE SYMPTOMS APPEAR AFTER ABOUT 20 WEEKS AND ACCOUNT FOR AIL WHICH DO NOT RECEIVE COBAIT IN ABOUT 50 weEks. The INCAPACITY OF COPPER WHEN ADMINISTERED alONE TO PREVENT THE PROGRESS OF THE SYMPTOMS AND ITS EFFECT WHEN SUPERIMPOSED ON COBALT TREATMENT IS OBVIOUS.

Reproduced from Bull. Council Sci. Ind. Research (Australia). (Merston and McDonald).

prevent the onset of untoward symptoms in sheep grazing on bush sick country. Following the announcement of the effect which cobalt exerted on animals suffering from coast disease, Askew and Dixon (1936) demonstrated that cobalt supplements were completely effective as a preventive suggests that pine, nakaturuitis and salt sickness, which apparently evidence identical symptoms, may be the result of a breakdown in the chain of metabolic events for which cobalt provides a link ; or not unlikely, they may indeed be of identical etiology, resulting from a metabolic disturbance 
caused directly from a partial or absolute shortage of cobalt in the fodder of the affected areas.

Coast disease, in some regions, is a rather more complicated syndrome than that resulting from cobalt deficiency. While it shares the symptoms of lethargy, wasting and anæmia with the other maladies which respond to a small supplement of cobalt, sporadic outbreaks of ataxia are frequently observed in young lambs born of ewes which have spent a relatively short sojoum during their pregnancy on certain parts of the littoral.

This condition, which results from degenerative changes in the spinal cord, although strictly regional also, is not invariably confined to areas where coast disease is enzootic. While the resulting lesions of demyelination are anatomically related to those observed in the enzootic paraplegia (renguerra) reported to occur among lambs bred in certain areas in the Peruvian Andes, and to those of swayback, which accounts from time to time for many lambs in certain parts of England, the underlying cause may possibly be distinct. The similar condition, enzootic ataxia of lambs in the Gin Gin area of Western Australia, which Bennetts has recently attributed to copper deficiency and shown to be overcome if the pregnant ewes on this area are supplemented with small amounts of copper, is, however, apparently closely related etiologically with that observed on the affected littoral ; for our experiments have amply demonstrated that small amounts of copper are essential to maintain cobalt-treated animals in good health while depastured on the areas where both ataxia and coast disease occur, notwith. standing the fact that supplementing with copper neither alleviates the symptoms of coast disease nor prevents the appearance of the anæmia and fatal decline if unaccompanied by cobalt.

The findings focus attention again on the possible physiological importance of those traces of elements, usually considered exotic, which have been demon. strated to be constantly present in living tissues, and furthermore, the discovery adds yet another example of the remarkable species difference in the behaviour of living organisms towards the nutritional environment; which, with little doubt, reflects subtle differences in the nature of the underlying metabolic processes.

The fact that horses exhibit no untoward symptoms when confined in their grazing to littoral tracts where ruminants will progressively decline and expire if left unsupplemented with cobalt is at present a fascinating subject for speculation, which may be solved when our knowledge of the role which cobalt assumes in the normal physiological function of some animals is extended.

A full description of the investigations of coast disease appears in monograph form in a Bulletin of the Council for Scientific and Industrial Research (1937). The references in the literature to similar maladies mentioned above are discussed in further detail there.

\section{Obituary}

Dr. A. B. Rendle, F.R.S.

A LFRED BARTON RENDLE, who died at
Leatherhead on January 11, was one of the
leading British systematic botanists, and had
been keper of botany in the British Museum
(Natural History) from 1906 until his retirement
in 1930.

Born in London on January 19, 1865, he was educated at St. Olave's School, Southwark, and St. John's College, Cambridge, where he studied botany under Vines. In 1888, he was appointed assistant in the Department of Botany in the British Museum (Natural History), being placed in charge of the Monocotyledons and Apetalæ. It was characteristic of Rendle that his first taxonomic paper was not published until five years later, when he had mastered the technique of the subject. His work was consistently thorough, and the fact that he was able to accomplish so much is a tribute to his unremitting industry. As lecturer in botany at the Birkbeck Institute, Rendle kept in touch with academic circles, and in 1904 the first volume of his "Classification

\section{Notices}

of Flowering Plants", comprising the Gymnosperms and Monocotyledons, was published by the Cambridge University Press. Ho described it modestly in the preface as "an attempt to give the student who has some acquaintance with botany a systematic account of the Flowering plants", but it was much more than this. By consultation of original memoirs as well as works of reference, Rendle had enriched it with many observations relating to embryology, anatomy, ecology, pollination and modes of fruit and seed dispersal, as well as with notes on the more outstanding types found in the various families. The second volume, including the Dicotyledons, appeared in 1925, and a new edition of vol. 1 in 1930.

Rendle fully appreciated the importance of the diffusion of scientific knowledge among the general public, and of closer relations between botanical theory and horticultural practice. $\mathrm{He}$ regularly attended the meetings of the British Association, and was president of Section $K$ (Botany) at Newcastle in 1916. His knowledge of exotic flores and vegetation 